\title{
Electromyography features during physical and imagined standing up in healthy young adults, Phitsanulok, Thailand
}

\author{
Kanokwan Srisupornkornkool, Kanphajee Sornkaew, \\ Kittithat Chatkanjanakool, Chayanit Ampairattana and \\ Pariyanoot Pongtasom \\ Department of Physical Therapy, Naresuan University, Phitsanulok, Thailand \\ Sompiya Somthavil and Onuma Boonyarom \\ Kasetsart University - Kamphaeng Saen Campus, Nakhon Pathom, Thailand, and \\ Kornanong Yuenyongchaiwat and Khajonsak Pongpanit \\ Thammasat University - Rangsit Campus, Khlong Luang, Thailand
}

\begin{abstract}
Purpose - To compare the electromyography (EMG) features during physical and imagined standing up in healthy young adults.

Design/methodology/approach - Twenty-two participants (ages ranged from 20-29 years old) were recruited to participate in this study. Electrodes were attached to the rectus femoris, biceps femoris, tibialis anterior and the medial gastrocnemius muscles of both sides to monitor the EMG features during physical and imagined standing up. The \% maximal voluntary contraction (\%MVC), onset and duration were calculated.

Findings - The onset and duration of each muscle of both sides had no statistically significant differences between physical and imagined standing up $(p>0.05)$. The $\% \mathrm{MVC}$ of all four muscles during physical standing up was statistically significantly higher than during imagined standing up $(\phi<0.05)$ on both sides. Moreover, the tibialis anterior muscle of both sides showed a statistically significant contraction before the other muscles $(p<0.05)$ during physical and imagined standing up.

Originality/value - Muscles can be activated during imagined movement, and the patterns of muscle activity during physical and imagined standing up were similar. Imagined movement may be used in rehabilitation as an alternative or additional technique combined with other techniques to enhance the STS skill.
\end{abstract}

Keywords Electromyography, Motor imagery, Standing up, Thailand

Paper type Research paper

\section{Introduction}

Sit-to-stand (STS) is considered to be a crucial basic movement for our daily activities. This movement can also indicate the development of self-help, as well as movement and balancing

(C) Kanokwan Srisupornkornkoo, Kanphajee Sornkaew, Kittithat Chatkanjanakool, Chayanit Ampairattana, Pariyanoot Pongtasom, Sompiya Somthavil, Onuma Boonyarom, Kornanong Yuenyongchaiwat and Khajonsak Pongpanit. Published in the Journal of Health Research. Published by Emerald Publishing Limited. This article is published under the Creative Commons Attribution (CCBY 4.0) license. Anyone may reproduce, distribute, translate and create derivative works of this article (for both commercial and non-commercial purposes), subject to full attribution to the original publication and authors. The full terms of this license may be seen at $\mathrm{http}$ ://creativecommons.org/licences/by/4.0/legalcode

The researchers thank the participants for their time in taking part in this study. Also, the authors acknowledge the Physical Therapy Department, Allied Health Science Faculty, Naresuan University, and Thammasat University, as well as the Sports Science Faculty, Kasetsart University, for their support.

Conflicts of interest statement. The authors declare that there is no conflict of interest.

EMG features in standing up healthy young adults

Received 9 August 2019 Revised 18 November 2019 11 December 2019 Accepted 13 December 2019 
JHR

35,1

90

abilities. To perform STS, the center of mass of the body must move forward and upward to a higher position. Consequently, the base of support is adjusted from a wider base to a narrow base. That is, the base from the thighs and the feet is altered to the feet only. So, performing STS relies on balancing control ability [1-4] and muscle strength [5-7], especially leg muscles, as $72 \%$ of the knee extensor muscles will be used during STS. Muscle strength, then, becomes one of the most essential factors [1] for building up an STS ability that will lead to effective and safe STS performance [8].

Enhancing STS capability can be done through (1) performing resistance exercises dealing with external resistance against muscle shortening $[9,10]$ and $(2)$ performing taskspecific functions focusing on repeatedly performing STS to build up leg muscle strength leading to safe STS performance [11]. However, the two mentioned workouts can be limited for people who have muscle weakness and disability. Hence, a study on how to stimulate the central nervous system, especially related to motor planning, would be beneficial. This will help support the motor system to interact better with the target organs in performing the desired activities effectively. The method used at present is known as "Motor imagery" or MI. The process of MI is quite similar to physical movement, as it shares the same movement similarities in terms of the movement period per distance [12], movement patterns [13], and the speed-accuracy tradeoff according to Fitts's law [14]. Likewise, neurophysiological evidence supports a unitary mechanism for action representation and execution [15]. Brain imaging also points to common loci of cortical activation between motor imagery and execution [16-18], and similarly, the excitability of the corticomotor pathway, in terms of temporal and spatial characteristics between motor imagery and actual movements $[19,20]$. These shared similarities will exhibit both simple movement and complex body movement. Thus, it can be said that MI imitates body movement but will not display actual movement.

The MI will mainly focus on body movement, so the study of MI is a significant aspect of the medical field concerning movement rehabilitation. Previous research showed that the process of MI could increase muscle strength [21], arm movement speed [22], hip joint movement angle [23] and balancing control ability [24]. Nonetheless, after going through previous literature reviews related to STS, it was found that the research on the influence of MI on STS is still rare because most research tends to emphasize the mental chronometry, proving there is no difference in terms of the length of both physical movement and MI. This evidence follows Fitts's law of arms, hands and walking movement [25, 26]. According to the STS study, it is revealed that there is no difference in terms of the period of time during actual and imagined STS [27]. Although most evidence supports the above statement, including particular body movements, such as moving the arms, or full-body movements such as walking or standing up, there is still no certain proof demonstrating that both movements are completely the same or different in all measure outcomes reflecting movement effectiveness and efficiency.

It is possible that, during STS imagery, the specific muscles are stimulated by the nervous system, and the force is then created, even though motor imagery does not generate overt movement. It has been shown to produce specific, patterned and level-attenuated EMG activity in the involved muscles during motor imagery [28-31]. Electromyography (EMG) activity occurring during MI might originate from an incomplete motor command inhibition [32], leading to tiny muscular contractions that reflected in the magnitude of EMG activity [33]. Despite the studies investigating the result of STS imagery, the research did not go further to examine the quality of movement, such as muscle activity. Since this property may be an important element of the effectiveness of motor imagery as a rehabilitation technique, this study examined the influence of STS imagery on muscle activity by evaluating STS efficiency with surface EMG. This EMG recording reflects the activity of superficial muscle fibers [34], and the evaluation was a noninvasive method that was easy and safe for the 
patient with no risks or pain. The rectus femoris, biceps femoris, medial gastrocnemius and tibialis anterior of both legs were monitored by EMG during imagined standing up and physical standing up, as it is believed these muscles create force and have more functions during STS [35, 36]. Further, we hypothesized that the patterns of muscle activity during physical and imagined standing up would be similar. Of particular interest, the current study aimed to compare the EMG features during physical and imagined standing up in healthy young adults. The productive outcomes from this study formed the basis for developing an enhanced program for people faced with defective movement.

\section{Methods}

Study design

This research was an experimental design and aimed to monitor EMG during physical and imagined STS.

\section{Participants}

Twenty-two healthy young adults (20-29 years) took part in the study. Based on a previous study [37], a statistical power of $80 \%$ was used to determine the sample size. Participants were recruited from the local university's student and staff population, as well as from people living around Nareasuan University, Phitsanulok Thailand. All participants were screened to ensure they had no impairment of standing up from a sitting position multiple times per session. The screening also ensured they had a normal body mass index (BMI; normal $=18.5-24.5 \mathrm{~kg} / \mathrm{m}^{2}$ ), no mental disorders or significant medical history, or current problems affecting balance or everyday motor function. Participants were screened for brain function ability, imagery ability and physical activity level by a mini-mental state examination (MMSE), a movement imagery questionnaire-revised (MIQ-R) and a habitual physical activity score, respectively. Participants with an MMSE score below 22, MIQ-R score below 20, or habitual physical activity score over six were excluded. Details of the participants are shown in Table 1.

\section{Experimental procedures}

The experiment was conducted in a quiet room within a laboratory suite. Participants were instructed to come dressed in comfortable clothing. They were asked to take their seat on a

\begin{tabular}{ll}
\hline Physical characteristics & Mean $\pm \mathrm{SD}$ \\
\hline Age (years) & $23.5 \pm 2.63$ \\
Body weight (kg) & $57.93 \pm 8.97$ \\
Height (cm) & $164.76 \pm 10.82$ \\
BMI (kg/m²) & $21.28 \pm 1.74$ \\
MMSE score & $28.91 \pm 1.44$ \\
MIQ-R; kinesthetic imagery (KI) & $27 \pm 1.75$ \\
MIQ-R; visual imagery (VI) & $27 \pm 1.98$ \\
Habitual physical activity & $5.74 \pm 0.16$ \\
Vividness & $1.32 \pm 0.48$ \\
HRV (LF: HF); during STS & $66: 28$ \\
HRV (LF: HF); during MI & $55: 45$
\end{tabular}

Note(s): BMI = body mass index; MMSE = mini-mental state examination; MIQ-R = movement imagery questionnaire-revised; $\mathrm{HRV}=$ heart rate variability; $\mathrm{LF}=$ low frequency; $\mathrm{HF}=$ high frequency; $\mathrm{STS}=$ physical sit to stand; $\mathrm{MI}=$ imagined sit to stand

Table 1. Physical characteristics
EMG features in standing up healthy young adults 
JHR

35,1

\section{2}

vertically adjustable chair set to the height of their lower legs. Participants' feet rested on the floor with their heels approximately $10 \mathrm{~cm}$ apart. Participants' ankles were positioned with $\sim 10^{\circ}$ of dorsiflexion and knees with $\sim 100-105^{\circ}$ of flexion [38] using a handheld goniometer. Participants were asked to keep their arms by their sides. EMG electrodes were attached to the participants' rectus femoris, biceps femoris, tibialis anterior and medial gastrocnemius muscles of both legs to measure EMG activity.

The EMG activity of the rectus femoris, biceps femoris, tibialis anterior and medial gastrocnemius muscles was monitored using silver electrodes with a $0.5 \mathrm{~cm}$ active surface. The skin was first dry-shaved and then cleaned with an alcohol swab before electrode placement to decrease impedance. Two electrodes were placed $2 \mathrm{~cm}$ apart on each muscle belly in line with the fiber direction. A ground electrode was attached to the participant's right knee over the lateral epicondyle [39]. Before starting the experiment, the intra-rater reliability for monitoring EMG signals was determined using the intraclass correlation coefficient (ICC) model 3,k. The finding showed the highest level of reliability. EMG signals were recorded at $1500 \mathrm{~Hz}$ using an 8-channel wireless sEMG system (MyoMuscle MR3 3.8.6; Noraxon, AZ, USA). The EMG data from the MVC test and during physical and imagined STS was filtered between a $20-450 \mathrm{~Hz}$ bandpass and calculated using a root mean square with a window of $20 \mathrm{~ms}$ for each muscle during the static end position.

All subjects were asked to perform MVC of all muscles: rectus femoris, biceps femoris, tibialis anterior and medial gastrocnemius. For the rectus femoris, subjects were seated at the edge of the bed with their feet firmly on the ground. The researcher asked subjects to extend one of their knees against maximum resistance without their trunk bending backward [40]. For the biceps femoris, subjects were prone with their thighs strapped with a belt to the testing bed to prevent compensation. The researcher asked subjects to bend one of their knees against maximum resistance [41]. For the tibialis anterior, subjects were in the long sitting position with the testing leg on the quadricep board. The researcher asked subjects to flex their ankle inwardly against maximum resistance [42]. For the medial gastrocnemius, subjects were in the long sitting position, and feet were firmly on the wall. The researcher asked subjects to push their toes against the wall while flexing their heels away from the wall. In all the MVC testing, the researcher asked the subjects to slowly increase the force to maximum effort and hold for $5 \mathrm{~s}$. Subjects were asked to perform three trials for each MVC testing in each muscle with a pausing period of $30 \mathrm{~s}$ between each MVC testing to let the EMG signal come back to baseline [39]. Subjects rested for 90 seconds between muscle testing. During the tests, subjects were instructed to avoid any jerky contraction to decrease the chance of injury. The researcher gave consistent verbal encouragement to the subjects for performing the MVC. The EMG data of each muscle's MVC was recorded and used for normalization processes. MVC was measured in units of the kilo-ohm $(\mathrm{k} \Omega)$. After the MVC testing, the subjects rested at least 30 minutes to prevent muscle fatigue before starting the performance of physical and imagined STS.

Next, the EMG signals of eight muscles were recorded during three instances of physical and imagined STS conditions. Each participant first performed the physical STS movement (three recorded trials), followed by the imagined STS movement (three recorded trials), with 1-5 minutes of rest in between or however long was needed before they exhibited no sign of fatigue. Each set of three recorded trials was preceded by two practice trials. In each trial, the participant awaited an instruction, "Ready...Go," and then performed a physical or imagined STS movement at their natural speed. While performing an imagined movement, the participants had to close their eyes and feel themselves standing up. They were asked to say out loud when they felt they had completed the STS movement and were "standing comfortably and steadily" (or imagined doing so). Participants were then asked to sit down, relax and prepare for the next trial. The average amplitude of each condition's signal was expressed as a percentage of the MVC for that 
muscle. The onset and duration of EMG activity were determined during the performance of physical and imagined STS.

After that, the EMG data of each task was used to calculate the \% MVC of each muscle (calculated by a computer program) using the following equation:

$$
\% \mathrm{MVC}=\frac{\text { Test EMG-Resting } \mathrm{EMG}_{0}}{\text { MVC of each muscle-Resting EMG }} \times 100
$$

EMG features in standing up healthy young adults

The onset and duration (sec) of muscle activities were also calculated. Onset was determined when the voltage exceeded baseline values by at least three standard deviations within $25 \mathrm{~ms}$ [28]. The action onset time on EMG, identified by the computer, was visually inspected. The duration of muscle activity was calculated by subtracting the offset time from the onset time. The EMG measurement was repeated three times, and the average value was used for analysis. An example of the EMG measurement during physical and imagined STS is shown in Figure 1.

Heart rate variability (HRV) was monitored using a V800 polar heart rate monitor (Polar Electro Ltd., Finland) throughout the performance of physical and imagined STS at a sampling rate of $1000 \mathrm{~Hz}$. The HRV was analyzed by linear method (time and frequency domains) by Kubios HRV software version 3.0.2 (Biosignal Analysis and Medical Imaging Group, University of Eastern Finland, Finland), according to the task force of the European Society of Cardiology and the North American Society of Pacing and Electrophysiology. The low frequency (LF) between $0.04-0.15 \mathrm{~Hz}$ predominantly indicated a sympathetic tone, while the high frequency $(\mathrm{HF})$ between $0.15-0.4 \mathrm{~Hz}$ indicated a parasympathetic tone. Spectral components were obtained in normalized units (nu). In conditions involving imagined movement, participants were asked to provide a vivid judgment after the experimental trials. For doing so, participants indicated on a 5-point scale how vividly they felt they had been able

Lt Rectus femoris

Lt Tibialis anterior

Lt Biceps femoris

Lt Gastrocnemius

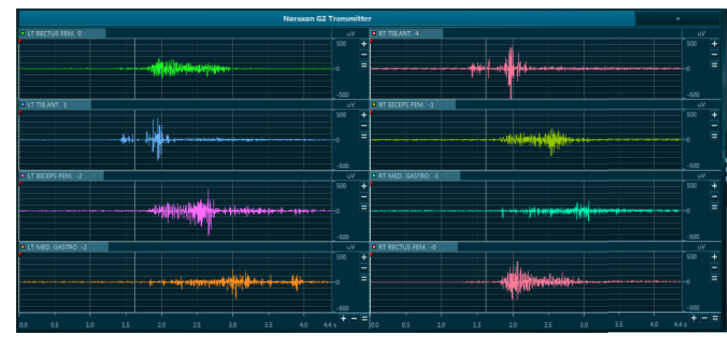

(a)

Lt Rectus femoris

Lt Tibialis anterior

Lt Biceps femoris

Lt Gastrocnemius

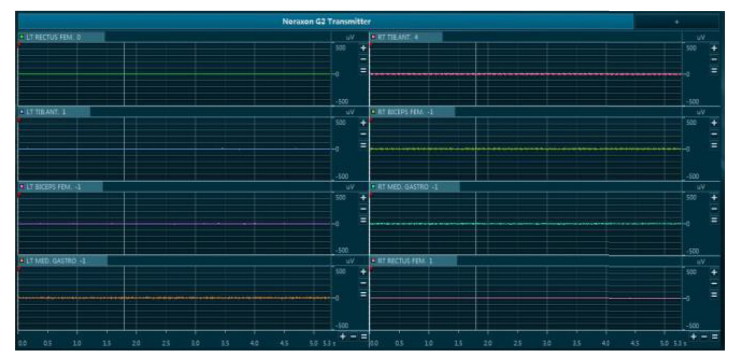

(b)
Rt Tibialis anterior

Rt Biceps femoris

Rt Gastrocnemius

Rt Rectus femoris

Rt Tibialis anterior

Rt Biceps femoris

Rt Gastrocnemius

Rt Rectus femoris
Figure 1. An example of the EMG measurement during physical (a) and imagined STS (b)

Note(s): STS = sit to stand; Rt $=$ Right; $\mathrm{Lt}=\mathrm{Left}$ 
JHR

35,1

94

to imagine the movement $(1=$ perfectly clear and as vivid as the feel of actual movement, $2=$ clear and reasonably vivid, $3=$ somewhat clear and vivid, $4=$ vague and dim and $5=$ no image at all). The HRV and vividness were used for monitoring imagined movement.

\section{Statistical analysis}

$\% \mathrm{MVC}$, onset, and duration of muscle activity were expressed as a mean and standard error of the mean. \%MVC and onset of muscle activity were analyzed using the Friedman test for within muscle effects. Post hoc means comparisons were performed using the Wilcoxon signed ranks test. A Wilcoxon signed-rank test was also used to investigate the differences either between the physical and imagined STS or the right and left legs of \%MVC and onset. The level of significance was set at 0.05 .

The duration of muscle activity was analyzed using the Repeated measures ANOVA test within muscle effects. A paired $t$-test was also used to analyze the differences between the physical and imagined STS, as well as the right and left legs of the duration of muscle activity. The level of significance was set at 0.05 .

\section{Ethical considerations}

This study was approved by the Ethics Committee (HSSREC) of Naresuan University (IRB No. 0197/60).

\section{Results}

The 22 healthy, young adults (20-29 years) participating in this study had no impaired ability to stand up from a sitting position and had no significant medical history or current problems affecting balance or everyday motor function. Participants also had normal BMI levels, cognitive function, motor imagery and sedentary lifestyles. Mean scores of age, body weight, height, BMI, MMSE, MIQ-R and habitual physical activity are shown in Table 1.

\section{The onset of muscle activity during physical and imagined STS}

The tibialis anterior muscle was activated first, either performing physical STS or imagined STS. The onset of tibialis anterior muscle activity was significantly faster than the medial gastrocnemius and biceps femoris muscles $(p<0.05)$. The onset of rectus femoris muscle activity was also faster than biceps femoris $(p<0.05)$. The pattern of muscle activities was similar not only during physical and imagined STS, but also for both the right and left legs $(p>0.05)$ There was no significant difference in the onset of each muscle activity during physical and imagined STS $(\phi>0.05)$. Also, the onset of each muscle activity and the condition of the right and left leg were similar $(p>0.05)$ (Table 2 and Figure 2).

\section{Duration of muscle activity during physical and imagined STS}

There was no significant difference in the duration of each muscle activity during physical and imagined STS $(p>0.05)$. Unsurprisingly, the duration of each muscle activity and the condition of the right and left leg were similar $(p>0.05)$ (Table 3 ).

\section{Maximal voluntary contraction (\%MVC)}

The $\%$ MVC of each muscle of both legs during imagined STS was lower than during physical STS $(p<0.05)$. There was no significant difference in the \%MVC of each muscle between the right and left legs during physical STS $(p>0.05)$, whereas the $\% \mathrm{MVC}$ of the tibialis anterior and medial gastrocnemius during imagined STS of the left legs was greater than that of the right legs $(p<0.05)$ (Table 4). 


\begin{tabular}{|c|c|c|c|c|c|c|}
\hline \multirow[b]{2}{*}{ Side } & \multirow[b]{2}{*}{ Muscle } & \multicolumn{2}{|c|}{ Condition } & \multirow{2}{*}{$\begin{array}{c}p \text {-value } \\
\text { [between STS } \\
\text { and MI] }\end{array}$} & \multirow{2}{*}{$\begin{array}{c}p \text {-value } \\
\text { [between right } \\
\text { and left legs] }\end{array}$} & \multirow{2}{*}{$\begin{array}{l}\text { EMG features } \\
\text { in standing up } \\
\text { healthy young }\end{array}$} \\
\hline & & $\begin{array}{l}\text { STS Mean } \pm \text { SEM } \\
\text { (median) }[\text { Max-Min }]\end{array}$ & $\begin{array}{c}\text { MI Mean } \pm \text { SEM } \\
\text { (median) [Max-Min] }\end{array}$ & & & \\
\hline \multirow[t]{7}{*}{ Right } & Rectus femoris & $\begin{array}{l}0.89 \pm 0.19(0.45) \\
{[0.00-2.08]}\end{array}$ & $\begin{array}{l}0.89 \pm 0.19(0.45) \\
{[0.00-2.08]}\end{array}$ & 0.317 & $\begin{array}{r}\text { STS } 0.317 \\
\text { MI } 1.000\end{array}$ & ults \\
\hline & Biceps femoris & $\begin{array}{l}1.02 \pm 0.19^{1}(0.52) \\
{[0.00-2.14]}\end{array}$ & $\begin{array}{l}1.02 \pm 0.19^{1}(0.52) \\
{[0.00-2.14]}\end{array}$ & 1.000 & $\begin{array}{r}\text { STS } 0.655 \\
\text { MI } 0.655\end{array}$ & 95 \\
\hline & Tibialis anterior & $\begin{array}{l}0.68 \pm 0.16^{2}(0.00) \\
{[0.00-1.74]}\end{array}$ & $\begin{array}{l}0.66 \pm 0.16^{2}(0.00) \\
{[0.00-1.64]}\end{array}$ & 1.000 & $\begin{array}{r}\text { STS } 0.109 \\
\text { MI } 0.109\end{array}$ & \\
\hline & $\begin{array}{l}\text { Medial } \\
\text { gastrocnemius }\end{array}$ & $\begin{array}{l}0.94 \pm 0.19^{3}(0.49) \\
{[0.00-2.25]}\end{array}$ & $\begin{array}{l}0.94 \pm 0.19^{3}(0.49) \\
{[0.00-2.25]}\end{array}$ & 1.000 & $\begin{array}{r}\text { STS } 0.180 \\
\text { MI } 0.180\end{array}$ & \\
\hline & $p$-value & RF vs $B F 0.017$ & RF vs $B F 0.017$ & & & \\
\hline & & BF vs TA 0.000 & BF vs TA 0.000 & & & \\
\hline & & TA vs MG 0.001 & TA vs MG 0.001 & & & \\
\hline \multirow[t]{7}{*}{ Left } & Rectus femoris & $\begin{array}{l}0.89 \pm 0.19(0.45) \\
{[0.00-2.08]}\end{array}$ & $\begin{array}{l}0.89 \pm 0.19(0.45) \\
{[0.00-2.08]}\end{array}$ & 1.000 & & \\
\hline & Biceps femoris & $\begin{array}{l}1.02 \pm 0.19^{1}(0.52) \\
{[0.00-2.14]}\end{array}$ & $\begin{array}{l}1.01 \pm 0.19^{1}(0.52) \\
{[0.00-2.14]}\end{array}$ & 1.000 & & \\
\hline & Tibialis anterior & $\begin{array}{l}0.68 \pm 0.16^{2}(0.00) \\
{[0.00-1.74]}\end{array}$ & $\begin{array}{l}0.6 \pm 0.16^{2}(0.00) \\
{[0.00-1.64]}\end{array}$ & 1.000 & & \\
\hline & $\begin{array}{l}\text { Medial } \\
\text { gastrocnemius }\end{array}$ & $\begin{array}{l}0.94 \pm 0.19^{3}(0.45) \\
{[0.00-2.25]}\end{array}$ & $\begin{array}{l}0.94 \pm 0.19^{3}(0.45) \\
{[0.00-2.25]}\end{array}$ & 1.000 & & \\
\hline & $p$-value & RF vs BF 0.010 & RF vs $B F 0.010$ & & & \\
\hline & & BF vs TA 0.000 & BF vs TA 0.000 & & & \\
\hline & & TA vs MG 0.003 & TA vs MG 0.003 & & & Mean of onset of \\
\hline \multicolumn{7}{|c|}{$\begin{array}{l}\text { Note(s): significant difference was tested by the Wilcoxon Signed Ranks; STS = physical sit to stand; muscle activity during } \\
\mathrm{MI}=\text { imagined sit to stand; } \mathrm{RF}=\text { rectus femoris; } \mathrm{BF}=\text { biceps femoris; TA }=\text { tibialis anterior; } \mathrm{MG}=\text { medial } \\
\text { ghysical and imagined } \\
\text { compared with } \mathrm{BF}(\phi<0.05) ;{ }^{3}=\text { significant difference when compared with } \mathrm{TA}(\phi<0.05)\end{array}$} \\
\hline
\end{tabular}

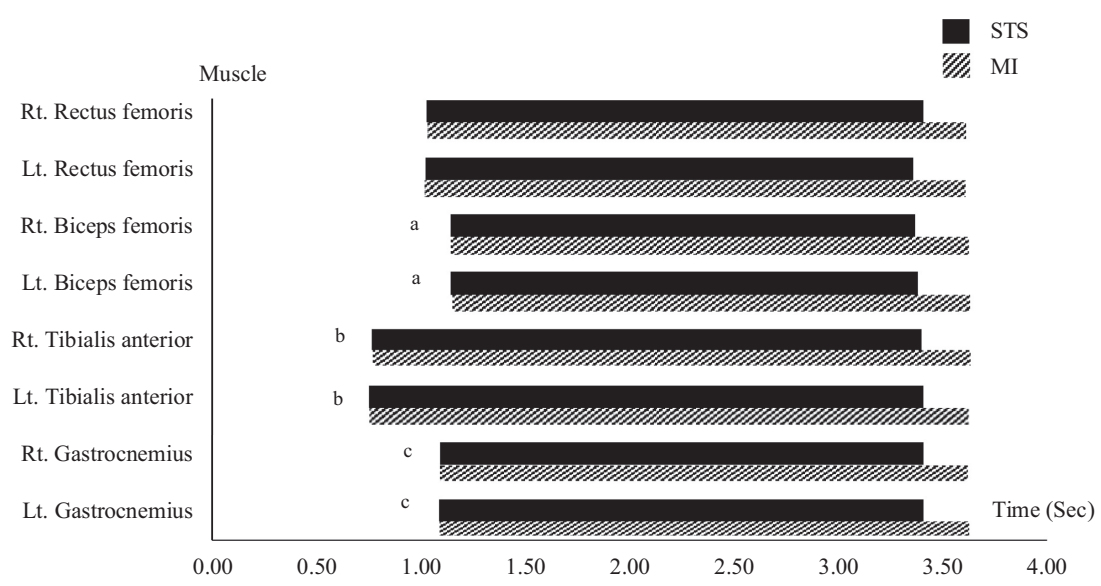

Note(s): Significant difference was tested by the Wilcoxon Signed Ranks; STS = physical sit to stand; $\mathrm{MI}=$ imagined sit to stand; Rt = Right; $\mathrm{Lt}=\mathrm{Left} ; \mathrm{a}=$ significant difference when compared with RF $(p<0.05) ; \mathrm{b}=$ significant difference when compared with BF $(p<0.05) ; \mathrm{c}=$ significant difference when compared with TA $(p<0.05)$

Figure 2. Onset of muscle activity during physical and imagined STS 


\begin{tabular}{|c|c|c|c|c|c|}
\hline \multirow[b]{2}{*}{ Muscles } & \multirow[b]{2}{*}{ Side } & \multicolumn{2}{|c|}{ Conditions } & \multirow{2}{*}{$\begin{array}{c}p \text {-value } \\
\text { [between } \\
\text { STS and MI] }\end{array}$} & \multirow{2}{*}{$\begin{array}{c}p \text {-value } \\
\text { [between } \\
\text { right and left } \\
\text { legs] }\end{array}$} \\
\hline & & $\begin{array}{c}\text { STS Mean } \pm \text { SEM } \\
{[\text { Max-Min] }}\end{array}$ & $\begin{array}{l}\text { MIMean } \pm \text { SEM } \\
{[\text { Max-Min] }}\end{array}$ & & \\
\hline \multirow[t]{2}{*}{ Rectus femoris } & Right & $2.17 \pm 0.07[1.41-2.71]$ & $2.16 \pm 0.14[0.63-3.52]$ & 0.626 & STS 0.180 \\
\hline & Left & $2.12 \pm 0.08[1.29-2.71]$ & $2.17 \pm 0.14[0.63-3.52]$ & 0.485 & MI 0.180 \\
\hline \multirow[t]{2}{*}{ Biceps femoris } & Right & $1.99 \pm 0.08[0.99-2.48]$ & $2.04 \pm 0.13[0.48-3.22]$ & 0.590 & STS 0.285 \\
\hline & Left & $2.00 \pm 0.08[0.99-2.48]$ & $2.04 \pm 0.13[0.48-3.22]$ & 0.627 & MI 0.893 \\
\hline Tibialis & Right & $2.39 \pm 0.09[1.68-3.12]$ & $2.48 \pm 0.13[1.08-3.62]$ & 0.235 & STS 0.655 \\
\hline anterior & Left & $2.40 \pm 0.09[1.68-3.12]$ & $2.50 \pm 0.14[0.99-3.62]$ & 0.204 & MI 0.273 \\
\hline Medial & Right & $2.10 \pm 0.06[1.28-2.58]$ & $2.11 \pm 0.14[0.42-3.22]$ & 0.498 & STS 0.317 \\
\hline gastrocnemius & Left & $2.10 \pm 0.06[1.28-2.58]$ & $2.11 \pm 0.14[0.42-3.22]$ & 0.498 & MI 0.655 \\
\hline
\end{tabular}

Table 3.
Mean of duration of muscle activity during physical and imagined STS of four muscles of the right and left legs

Note(s): significant difference was tested by the paired $t$-tests; STS = physical sit to stand; $\mathrm{MI}=$ imagined sit to stand

\begin{tabular}{|c|c|c|c|c|c|}
\hline \multirow[b]{2}{*}{ Muscles } & \multirow[b]{2}{*}{ Side } & \multicolumn{2}{|c|}{ Conditions } & \multirow[b]{2}{*}{$\begin{array}{c}p \text {-value } \\
\text { [between } \\
\text { STS and MI] }\end{array}$} & \multirow{2}{*}{$\begin{array}{c}p \text {-value } \\
\text { [between } \\
\text { right and left } \\
\text { legs] }\end{array}$} \\
\hline & & $\begin{array}{l}\text { STS Mean } \pm \text { SEM } \\
\text { (median) [Max-Min] }\end{array}$ & $\begin{array}{l}\text { MI Mean } \pm \text { SEM } \\
\text { (median) [Max-Min] }\end{array}$ & & \\
\hline \multirow[t]{2}{*}{ Rectus femoris } & Right & $\begin{array}{l}43.79 \pm 3.12(40.33) \\
{[19.44-79.03]}\end{array}$ & $\begin{array}{l}1.49 \pm 0.31^{*}(0.92) \\
{[0.24-5.32]}\end{array}$ & 0.000 & \multirow[t]{2}{*}{$\begin{array}{r}\text { STS } 0.987 \\
\text { MI } 0.095\end{array}$} \\
\hline & Left & $\begin{array}{l}45.16 \pm 4.25(40.66) \\
{[15.09-92.68]}\end{array}$ & $\begin{array}{l}2.01 \pm 0.61^{*}(1.24) \\
{[0.29-14.09]}\end{array}$ & 0.000 & \\
\hline \multirow[t]{2}{*}{ Biceps femoris } & Right & $\begin{array}{l}16.73 \pm 1.71(13.66) \\
{[7.43-33.56]}\end{array}$ & $\begin{array}{l}0.80 \pm 0.11^{*}(0.61) \\
{[0.31-2.67]}\end{array}$ & 0.000 & \multirow[t]{2}{*}{$\begin{array}{r}\text { STS } 0.445 \\
\text { MI } 0.733\end{array}$} \\
\hline & Left & $\begin{array}{l}19.06 \pm 2.65(16.22) \\
{[0.40-44.43]}\end{array}$ & $\begin{array}{l}0.71 \pm 0.12^{*}(0.57) \\
{[0.15-3.00]}\end{array}$ & 0.000 & \\
\hline \multirow[t]{2}{*}{$\begin{array}{l}\text { Tibialis } \\
\text { anterior }\end{array}$} & Right & $\begin{array}{l}52.85 \pm 5.20(49.75) \\
{[13.20-96.41]}\end{array}$ & $\begin{array}{l}0.77 \pm 0.24^{*}(0.58) \\
{[0.20-5.77]}\end{array}$ & 0.000 & \multirow[t]{2}{*}{$\begin{array}{r}\text { STS } 0.709 \\
\text { MI } 0.001\end{array}$} \\
\hline & Left & $\begin{array}{l}55.50 \pm 5.41(59.23) \\
{[17.21-102.52]}\end{array}$ & $\begin{array}{l}1.34 \pm 0.40^{*}, \#(0.84) \\
{[0.31-9.48]}\end{array}$ & 0.000 & \\
\hline \multirow[t]{2}{*}{$\begin{array}{l}\text { Medial } \\
\text { gastrocnemius }\end{array}$} & Right & $\begin{array}{l}24.65 \pm 3.43(19.41) \\
{[7.03-72.95]}\end{array}$ & $\begin{array}{l}1.64 \pm 0.24^{*}(1.33) \\
{[0.67-5.88]}\end{array}$ & 0.000 & \multirow[t]{2}{*}{$\begin{array}{r}\text { STS } 0.200 \\
\text { MI } 0.006\end{array}$} \\
\hline & Left & $\begin{array}{l}21.36 \pm 2.99(17.48) \\
{[6.95-75.12]}\end{array}$ & $\begin{array}{l}2.36 \pm 0.27^{*, \#}(2.03) \\
{[0.70-6.17]}\end{array}$ & 0.000 & \\
\hline
\end{tabular}

Mean of \% MVC during physical and imagined STS of 4 muscles of the right and left legs
Note(s): significant difference was tested by the Wilcoxon Signed Ranks; STS = physical sit to stand; $\mathrm{MI}=$ imagined sit to stand; ${ }^{*}=$ significant difference between physical and imagined STS $(p<0.05)$; ${ }^{\#}=$ significant difference between right and left legs $(p<0.05)$

\section{Discussion}

Since all volunteers had a very clear vividness, most of their HRV variations during both physical and imagined standing up were at a low-frequency power. Thus, the process was run by the sympathetic nervous system, which confirms the research of Demougeot et al. [43] who examined the results arising from autonomic function during the imagined trunk, leg and wrist movements compared with actual movement and resting by measuring arterial pressure, heart rate and EMG. The result showed that, compared to resting, the rate of those three factors during imagery were increased drastically and significantly. Further, both arterial pressure and heart rate were similar during imagined movement and actual movement. The study from Bunno et al. [44] investigating changes in autonomic nervous system stimulation during imagery on the isometric contraction of the thenar muscle at $10 \%$ 
MVC and at $50 \% \mathrm{MVC}$ evaluated the low to high frequency of the HRV during resting, imagery and after imagery. The results revealed that the ratio between low and high frequencies at $50 \% \mathrm{MVC}$ during imagery was significantly increased when compared with the ratio during resting. Hence, it can be said that imagery can undoubtedly increase cardiac sympathetic nerve activity in the same way actual movement does. Therefore, it is clear that when there is an imagined movement, an autonomic nervous system function will be stimulated, especially in sympathetic nervous systems. This behavior mimics actual movement because the sympathetic nervous system is stimulated the same way during imagined movement and actual movement, resulting in a changing heart rate. So, from this study, it can be concluded that during imagery, the volunteers created an imagined movement.

Moreover, it was found that the functions of the four leg muscles, the rectus femoris, biceps femoris, tibialis anterior and medial gastrocnemius, are similar in terms of onset and duration of movement during physical and imagined STS. This indicates that the functions of both the central nervous system and motor system that work on actual and imagined movement are similar [15-20, 45-47]. This evidence supports the research of Solodkin et al. [20]claiming that the function of both the supplementary motor cortex and the lateral premotor cortex will be stimulated by imagined movement, especially kinesthetic imagery that will then stimulate the corticolateral primary motor cortex, and the nervous signal will go through the corticospinal tract. This kind of stimulation is similar to actual movement. Again, the study by Somthavil et al. [16] and Srisupornkornkool et al. [17] investigated the electroencephalography (EEG) during physical and imagined standing up of healthy older and young adults. The result indicated that theEEG patterns in the frontal lobe and temporal lobe during physical and imagined standing up are similar. Both lobes showed beta brainwave patterns, meaning that the brain was active or being stimulated to perform activities. In summary, the brain function during movement imagery is reasonably similar to the actual movement, principally at the frontal and temporal lobe.

During physical STS, there is more contraction of the four muscles than during movement imagery. This may be because, during imagery, the signal from the corticospinal tract is blocked by the premotor inhibition mechanism at the brain stem and spinal cord level[48]. However, this is not the complete blockage mechanism; the presence of the working muscles exists during imagery $[29,49]$. This evidence is in line with the study displaying the contraction of the four muscles during STS imagery, and the muscle contraction during imagery is greater than during resting before standing up [28-31]. For example, this proof is consistent with the study of Guillot et al. [29] investigating the reaction of nine arm muscles: the short and long head of the biceps brachii, the brachioradialis, the triceps brachii, the flexor carpi ulnaris, flexor carpi radialis, the anterior deltoid, the upper trapezius and the pectoralis major. The study was geared toward finding the consequence of the difference during dumbbell lifting and dumbbell lifting imagery and during resting of university students aged between 18 and 25. After EMG application, the results revealed that, during dumbbell lifting imagery compared with during resting, there was a significant contraction of all arm muscles. Further, the contraction of all muscles during dumbbell lifting was significantly greater than during dumbbell lifting imagery. Moreover, Lebon et al. [30], investigated the results during dumbbell lifting imagery by monitoring EMG during the performance of concentric, eccentric and isometric contractions. The findings showed that, during the three types of dumbbell lifting imagery, the median frequency was significantly increased when compared with resting time. In addition, the change of the median frequency can indicate the motor unit change and the conductivity of muscle fibers. So, this study has proven that imagination creates the transmission of nervous signals to the muscles. Oh et al. [28] also examined the movement imagery of the knee extensor muscles of chronic stroke patients using EMG. The investigation was done in five stages consisting of (1) before imagined standing up, (2) during imagined standing up, (3) imagined weight-bearing on feet during standing up, (4) imagined sitting down and (5) after imagery. It was found that the muscle function during imagined standing up and sitting down was increased significantly when compared with before imagery.
EMG features in standing up healthy young adults 
JHR

35,1

98

Moreover, the results indicated that the tibialis anterior muscles began their functions before others, followed by the rectus femoris, medial gastrocnemius and biceps femoris. These last three muscles exhibited a similar pattern both during standing up and standing up imagery of both sides, due to the reasons that, during standing up, the center of mass was shifted to the front, so the ankle needed to rely on the tibialis anterior muscle to maintain its balancing ability and durability to be ready before standing up. This finding is in accordance with the study of Khemlani et al. [50] which examined muscles used to perform STS. The result of the study revealed that, within flexion movement or the first stage of standing up, the body momentum will rise to the front, and the body weight will be more at both sides of the feet. Then, the tibialis anterior muscle will be activated before other muscles to maintain its balancing ability, helping to move forward to perform STS effectively. As a result of the present study, muscles can be activated during imagined movement and the patterns of muscle activity during physical and imagined standing up movement may be used in rehabilitation as an alternative or additional technique combined with other techniques to enhance the STS skill. However, to clearly understand the mechanism of imagined STS, it is necessary to explore age-related differences in muscle activity. Because of deterioration in the ability to perform the STS movement in older adults, they have often experienced a change in the mechanical properties of muscles and strategies adopted during the STS movement. Therefore, age-related differences in muscle activity during physical and imagined standing up should be evaluated in the future before using the information to develop rehabilitation programs for the elderly and people who present the inability to perform the STS skill.

Another finding from the current study is that, during imagination, the contraction of both the tibialis anterior and the medial gastrocnemius muscles on the right side was less than the left side, even though most of the volunteers have a right dominant foot. Hence, it would be useful to further investigate the relationship between the muscle and brain function during imagination with one's dominant foot.

\section{Conclusions}

In summary, muscles can be stimulated during imagined movement, although muscle activity is lower during physical movement. Interestingly, the patterns of muscle activity, such as the onset and duration during physical and imagined standing up were similar. Thus, imagined movement may be used in rehabilitation as an alternative or additional technique combined with other techniques to enhance the STS skill.

\section{References}

1. Fujimoto M, Chou LS. Dynamic balance control during sit-to-stand movement: an examination with the center of mass acceleration. J Biomech. 2012 Feb; 45(3): 543-8. doi: 10.1016/j.jbiomech. 2011.11.037.

2. Mong Y, Teo TW, Ng SS. 5-repetition sit-to-stand test in subjects with chronic stroke: reliability and validity. Arch Phys Med Rehabil. 2010 Mar; 91(3): 407-13. doi: 10.1016/j.apmr.2009.10.030.

3. $\mathrm{Ng}$ S. Balance ability, not muscle strength and exercise endurance, determines the performance of hemiparetic subjects on the timed-sit-to-stand test. Am J Phys Med Rehabil. 2010 Jun; 89(6): 497-504. doi: 10.1097/PHM.0b013e3181d3e90a.

4. Riley PO, Krebs DE, Popat RA. Biomechanical analysis of failed sit-to-stand. IEEE Trans Rehabil Eng. 1997 Dec; 5(4): 353-9. doi: 10.1109/86.650289.

5. Galli M, Cimolin V, Crivellini M, Campanini I. Quantitative analysis of sit to stand movement: experimental set-up definition and application to healthy and hemiplegic adults. Gait Posture. 2008 Jul; 28(1): 80-5. doi: 10.1016/j.gaitpost.2007.10.003.

6. Janssen WG, Bussmann HB, Stam HJ. Determinants of the sit-to-stand movement: a review. Phys Ther. 2002 Sep; 82(9): 866-79. 
7. Bohannon RW, Bubela DJ, Magasi SR, Wang YC, Gershon RC. Sit-to-stand test: performance and determinants across the age-span. Isokinet Exerc Sci. 2010; 18(4): 235-40. doi: 10.3233/IES2010-0389.

8. Hughes MA, Myers BS, Schenkman ML. The role of strength in rising from a chair in the functionally impaired elderly. J Biomech. 1996 Dec; 29(12): 1509-13.

EMG features in standing up healthy young adults

9. Schot PK, Knutzen KM, Poole SM, Mrotek LA. Sit-to-stand performance of older adults following strength training. Res Q Exerc Sport. 2003 Mar; 74(1): 1-8. doi: 10.1080/02701367.2003.10609058.

10. Schlicht J, Camaione DN, Owen SV. Effect of intense strength training on standing balance, walking speed, and sit-to-stand performance in older adults. J Gerontol A Biol Sci Med Sci. 2001 May; 56(5): M281-6. doi: 10.1093/gerona/56.5.m281.

11. Rosie J, Taylor D. Sit-to-stand as home exercise for mobility-limited adults over 80 years of ageGrandStand System may keep you standing? Age and Ageing. 2007 Sep; 36(5): 555-62. doi: 10. 1093/ageing/afm093.

12. Papaxanthis C, Schieppati M, Gentili R, Pozzo T. Imagined and actual arm movements have similar durations when performed under different conditions of direction and mass. Exp Brain Res. 2002 Apr; 143(4): 447-52. doi: 10.1007/s00221-002-1012-1.

13. Cerritelli B, Maruff P, Wilson P, Currie J. The effect of an external load on the force and timing components of mentally represented actions. Behav Brain Res. 2000 Feb; 108(1): 91-6. doi: 10.1016/ s0166-4328(99)00138-2.

14. Stevens JA. Interference effects demonstrate distinct roles for visual and motor imagery during the mental representation of human action. Cognition. 2005 Apr; 95(3): 329-50. doi: 10.1016/j. cognition.2004.02.008.

15. Clark S, Tremblay F, Ste-Marie D. Differential modulation of corticospinal excitability during observation, mental imagery and imitation of hand actions. Neuropsychologia. 2004; 42(1): 105-12. doi: 10.1016/s0028-3932(03)00144-1.

16. Somthavil S, Srisupornkornkool K, Rassameejan S, Boonyarom O. The effect of sit-tostand and imagined sit-to-stand on the electroencephalograms features of healthy elderly. Chula Med J. 2017; 61(6): 757-70.

17. Kanokwan S, Pramkamol W, Wipatcharee K, Warissara W, Siwarit R, Sompiya S, Onuma B, Mitra S. Age-related differences in brain activity during physical and imagined sit-to-stand in healthy young and older adults. J Phys Ther Sci. 2019 May; 31(5): 440-8. doi: 10.1589/ jpts.31.440.

18. Bakker M, De Lange FP, Helmich RC, Scheeringa R, Bloem BR, Toni I. Cerebral correlates of motor imagery of normal and precision gait. Neurolmage. 2008 Jul; 41(3): 998-1010. doi: 10.1016/j. neuroimage.2008.03.020.

19. Hashimoto R, Rothwell JC. Dynamic changes in corticospinal excitability during motor imagery. Exp Brain Res. 1999 Mar; 125(1): 75-81. doi: 10.1007/s002210050660.

20. Solodkin A, Hlustik P, Chen EE, Small SL. Fine modulation in network activation during motor execution and motor imagery. Cereb Cortex. 2004 Nov; 14(11): 1246-55. doi: 10.1093/cercor/bhh086.

21. Zijdewind I, Toering ST, Bessem B, Van Der Laan O, Diercks RL. Effects of imagery motor training on torque production of ankle plantar flexor muscles. Muscle Nerve. 2003 Aug; 28(2): 168-73. doi: 10.1002/mus.10406.

22. Gentili R, Papaxanthis C, Pozzo T. Improvement and generalization of arm motor performance through motor imagery practice. Neuroscience. 2006; 137(3): 761-72. doi: 10.1016/j.neuroscience.2005.10.013.

23. Williams JG, Odley JL, Callaghan M. Motor imagery boosts proprioceptive neuromuscular facilitation in the attainment and retention of range-of-motion at the hip joint. J Sport Sci Med. 2004 Sep; 3(3): 160-6.

24. Bae YH, Ko Y, Ha H, Ahn SY, Lee W, Lee SM. An efficacy study on improving balance and gait in subacute stroke patients by balance training with additional motor imagery: a pilot study. J Phys Ther Sci. 2015 Oct; 27(10): 3245-8. doi: 10.1589/jpts.27.3245. 
JHR

35,1

25. Parsons LM. Imagined spatial transformation of one's body. J Exp Psychol Gen. 1987 Jun; 116(2): 172-91.

26. Skoura X, Papaxanthis C, Vinter A, Pozzo T. Mentally represented motor actions in normal aging. I. Age effects on the temporal features of overt and covert execution of actions. Behav Brain Res. 2005 Dec 7; 165(2): 229-39. doi: 10.1016/j.bbr.2005.07.023.

27. Srisupornkornkool K. Effect of aging on the planning and execution of sit-to-stand movement. England: University of Warwick; 2014.

28. Oh DW, Kim JS, Kim SY, Yoo EY, Jeon HS. Effect of motor imagery training on symmetrical use of knee extensors during sit-to-stand and stand-to-sit tasks in post-stroke hemiparesis. Neurorehabilitation. 2010; 26(4): 307-15. doi: 10.3233/nre-2010-0567.

29. Guillot A, Lebon F, Rouffet D, Champely S, Doyon J, Collet C. Muscular responses during motor imagery as a function of muscle contraction types. Int J Psychophysiol. 2007 Oct; 66(1): 18-27. doi: 10.1016/j.ijpsycho.2007.05.009.

30. Lebon F, Rouffet D, Collet C, Guillot A. Modulation of EMG power spectrum frequency during motor imagery. Neurosci Lett. 2008 Apr; 435(3): 181-5. doi: 10.1016/j.neulet.2008.02.033.

31. Losana-Ferrer A, Manzanas-Lopez S, Cuenca-Martinez F, Paris-Alemany A, La Touche R. Effects of motor imagery and action observation on hand grip strength, electromyographic activity and intramuscular oxygenation in the hand gripping gesture: a randomized controlled trial. Hum Movement Sci. 2018 Apr; 58: 119-31. doi: 10.1016/j.humov.2018.01.011.

32. Jeannerod M. The representing brain - neural correlates of motor intention and imagery. Behav Brain Sci. 1994 Jun; 17(2): 187-202. doi: 10.1017/S0140525x00034026.

33. Bonnet M, Decety J, Jeannerod M, Requin J. Mental simulation of an action modulates the excitability of spinal reflex pathways in man. Brain Res Cogn Brain Res. 1997 Mar; 5(3): 221-8. doi: 10.1016/s0926-6410(96)00072-9.

34. Jeannerod M, Frak V. Mental imaging of motor activity in humans. Curr Opin Neurobiol. 1999 Dec; 9(6): 735-9. doi: 10.1016/s0959-4388(99)00038-0.

35. Caruthers EJ, Thomson JA, Chaudhari AMW, Schmitt LC, Best TM, Saul K, Siston RA. Individual muscle forces during a sit to stand transfer. Columbus: Ohio State University; 2014.

36. Cho S, Byeon H. Muscle activity of lower extremities for normal adults according to the type of chair and posture during sit-to-stand movement. Int J Biosci Biotechnol. 2015; 7(3): 51-60.

37. Burnfield JM, Shu Y, Buster TW, Taylor AP, McBride MM, Krause ME. Kinematic and electromyographic analyses of normal and device-assisted sit-to-stand transfers. Gait Posture. 2012 Jul; 36(3): 516-22. doi: 10.1016/j.gaitpost.2012.05.002.

38. Cheng PT, Liaw MY, Wong MK, Tang FT, Lee MY, Lin PS. The sit-to-stand movement in stroke patients and its correlation with falling. Arch Phys Med Rehabil. 1998 Sep; 79(9): 1043-6. doi: 10. 1016/s0003-9993(98)90168-x.

39. Cram JR, Kasman GS, Holtz J. Introduction to surface electromyography. Gaithersburg: Aspen Publication; 1998.

40. Oliveira N, Sanders RH. Effects of knee action phase and fatigue on Rectus Femoris and Biceps Femoris co-activation during the eggbeater kick. Hum Mov Sci. 2017 Jan; 51: 82-90. doi: 10.1016/j. humov.2016.11.006.

41. Worrell TW, Karst G, Adamczyk D, Moore R, Stanley C, Steimel B, et al. Influence of joint position on electromyographic and torque generation during maximal voluntary isometric contractions of the hamstrings and gluteus maximus muscles. J Orthop Sports Phys Ther. 2001 Dec; 31(12): 730-40. doi: 10.2519/jospt.2001.31.12.730.

42. Guzmán-Venegas RA, Bralic MP, Cordero JJ, Cavada G, Araneda OF. Concordance of the location of the innervation zone of the tibialis anterior muscle using voluntary and imposed contractions by electrostimulation. J Electromyogr Kines. 2016 Apr; 27: 18-23. doi: 10.1016/j. jelekin.2016.01.002. 
43. Demougeot L, Normand H, Denise P, Papaxanthis C. Discrete and effortful imagined movements do not specifically activate the autonomic nervous system. PLoS One. 2009 Aug; 4(8): e6769. doi: 10.1371/journal.pone.0006769.

44. Bunno Y, Suzuki T, Iwatsuki H. Effect of motor imagery on the spinal motor neurons excitability and autonomic nervous activity. J Kansai Phys Ther. 2016; 16: 31-6. doi: 10.11354/jkpt.16.31.

EMG features in standing up healthy young adults

46. Belkacem AN, Nishio S, Suzuki T, Ishiguro H, Hirata M. Neuromagnetic decoding of simultaneous bilateral hand movements for multidimensional brain-machine interfaces. IEEE Trans Neural Syst Rehabil Eng. 2018 Jun; 26(6): 1301-10. doi: 10.1109/TNSRE.2018.2837003.

47. Chen C, Zhang J, Belkacem AN, Zhang S, Xu R, Hao B, Gao Q, Shin D, Wang C, Ming D. GCausality brain connectivity differences of finger movements between motor execution and motor imagery. J Healthc Eng. 2019; 2019: 5068283. doi: 10.1155/2019/5068283.

48. Boulton H, Mitra S. Body posture modulates imagined arm movements and responds to them. J Neurophysiol. 2013 Dec; 110(11): 2617-26. doi: 10.1152/jn.00488.2013.

49. Duclos Y, Schmied A, Burle B, Burnet H, Rossi-Durand C. Anticipatory changes in human motoneuron discharge patterns during motor preparation. J Physiol. 2008 Feb 15; 586(4): 1017-28. doi: 10.1113/jphysiol.2007.145318.

50. Khemlani MM, Carr JH, Crosbie WJ. Muscle synergies and joint linkages in sit-to-stand under two initial foot positions. Clin Biomech (Bristol, Avon). 1999 May; 14(4): 236-46. doi: 10.1016/s02680033(98)00072-2.

\section{Corresponding author}

Kanokwan Srisupornkornkool can be contacted at: kanokwans@nu.ac.th

For instructions on how to order reprints of this article, please visit our website:

www.emeraldgrouppublishing.com/licensing/reprints.htm

Or contact us for further details: permissions@emeraldinsight.com 